\title{
Socio-Ecological Vulnerabilities and Major Cereal Crops Production in Bangladesh
}

Jatish C. Biswas ${ }^{1,3}$, A. F. M. T. Islam² ${ }^{2}$ M. M. Haque ${ }^{1}$, M. Maniruzzaman ${ }^{1}$, M. B. Hossain ${ }^{1}$, A. K. Choudhury ${ }^{2}$, U. A. Naher ${ }^{1}$, M. H. Ali ${ }^{3}$, W. Kabir ${ }^{3}$, N. Kalra ${ }^{3}$ and S. Rahnamayan ${ }^{4}$

1. Bangladesh Rice Research Institute, Gazipur 1701, Bangladesh

2. Bangladesh Agricultural Research Institute, Gazipur 1701, Bangladesh

3. Krishi Gobeshona Foundaion (KGF), Dhaka 1215, Bangladesh

4. Nature Inspired Computational Intelligence, (ECSE), UOIT, Oshawa Ontario L1G0C5, Canada

\begin{abstract}
Bangladesh enjoys food self-sufficiency or deficiency depending on crop damages by drought, floods, cyclones, storm/tidal surges and other natural hazards. Data on climate extremes were collected from literatures. Landsat images were analyzed for water availability. Arithmetic, geometric and weighted means were calculated for community vulnerability delineation using IDRISI3.2. About $12.64 \%$ populations live in disaster prone areas and their sensitivity to exposed hazards depends on financial capabilities. Crop area damages by natural hazards were the highest in Dhaka division followed by Rajshahi division during 2009-2014. The highest economic loss (\$613 million) was found in Barisal division followed by Dhaka (\$198.7 million) division. Flooding was the most damaging climate extreme followed by drought and hailstorm. Rice crops are frequently exposed to climate extremes and caused economic loss of $\$ 228$ million during 2009-2014. Economic losses were $<\$ 110$ to 1,000 ha $^{-1}$ because of wheat/maize areas damaged by natural hazards. The most vulnerable areas are situated in the south-west and north-west part of the country. The most affected areas (35.4\% of the country) had economic losses of $\$ 940-1,170 \mathrm{ha}^{-1}$. About 2-4.7 million households (HH) were affected by different natural hazards in different regions of the country. Flood affected HHs were predominant in northern and north-east regions of the country. Common adaptations to natural hazard exposures are crop switching and migration. The other adaptation options could be improvement of post disaster recovery efficiency through financial support, supplying seeds and other inputs based on seasonal suitability.
\end{abstract}

Key words: Cereals, climate change, flood, cyclones, storm/tidal surge, drought, economic loss.

\section{Introduction}

Major cereals in Bangladesh include rice and wheat of which rice is the staple food and grows year-round. Nowadays maize areas are expanding rapidly and have entered directly into food chain as a mixture of wheat flour and indirectly as feed of livestock. Rice covers almost $74 \%$ of total cropped area and contributes more than $93 \%$ of total grain production in Bangladesh [1]. Wheat is grown in winter mostly by utilizing residual moisture and covers about 0.44 million hectares (M ha). Maize is cultivated in both pre-monsoon and

Corresponding author: Md Mozammel Haque, Ph.D., senior scientific officer, research fields: greenhouse gas emission and soil fertility. winter season that covers about $0.33 \mathrm{M}$ ha in a year. National average yields are 4.38, 3.06 and $7.11 \mathrm{t} \cdot \mathrm{ha}^{-1}$ for rice, wheat and maize, respectively [1].

In future, more food will be required to feed ever growing population that has to come from unfavorable ecosystem like drought, salinity, flood, etc. [2, 3]. In 2025, net cultivated areas will be reduced to about $7.89 \mathrm{M}$ ha but have to produce enough to feed about 184 million people [4]. It will be very difficult, if not impossible, to produce sufficient food for South Asian people when climate extremes are increasing. The combined effects of rising temperatures, flooding, seasonal droughts and loss of arable lands are expected to decline cereal production in developing countries including Bangladesh [5]. 
Bangladesh is one of the most vulnerable countries to climate change in the world and enjoys either food self-sufficiency or deficiency depending on crop damages caused by drought, floods, cyclones and storm surges that are increasing recently [6, 7]. Drought affected about $74 \%$ areas of the country during 1949 to 1991; while flood occurs almost every year and can affect about $80 \%$ of the land [7]. Thus climate-induced natural disasters can damage crops partially or completely in Bangladesh. For example, cyclone Sidr hit Bangladesh in 2007 and caused \$3 billion loss in crop sector [8].

In south Asia, annual monsoon precipitation may remain unchanged, but winter months are likely to be warmer and drier in future [7] indicating that crops growing in winter season will suffer from drought and higher temperature effects. Besides, inter-annual climatic variability in Bangladesh is distinct and the probability of occurrence of extreme episodic/climatic events has increased in the last couple of decades and thus threatening food security of the country [9]. They also reported that if minimum temperature increases by $1{ }^{\circ} \mathrm{C}$, winter season rice yield-the major contributor in Bangladesh, will be reduced by 0.34 $\mathrm{t} \cdot \mathrm{ha}^{-1}$ that will be aggravated further with reduction in sunshine hours. Similarly, more than $10 \%$ yield reduction in wheat is likely if temperature rises by $1{ }^{\circ} \mathrm{C}$ [10]. Temperature rise by $0.5^{\circ} \mathrm{C}$ since 1950 is responsible for increased natural hazards globally, which is likely to increase in future [11].

The above stated problems clearly indicate that resilience building to climate change impact is necessary, which has been investigated through the identification of socio-ecological vulnerabilities of the country and economic loss patterns in rice, wheat and maize production along with strategic directions for sustained cereal production in Bangladesh.

\section{Materials and Methods}

Data were collected from Bangladesh Bureau of Statistics [1], Bangladesh Agricultural Research
Council (http://www.barc.gov.bd/), Bangladesh Delta Plan 2100 [12] and from existing available literatures. Data on economic losses of rice, wheat and maize crop damages during 2009-2014 and household (HH) income, disaster preparedness, disaster knowledge management and HHs affected by drought, flooding, waterlogging, cyclone, tornado, storm/tidal surge, thunderstorm, erosion, salinity, hailstorm were collected from 64 districts following stratified two-stage random sampling technique [13] for delineating vulnerable areas of the country. A total of 4,945 mauzas/mahallas (the smallest administrative unit) were considered in the first stage and then 143,980 HHs were selected for data collection. Pre-tested questionnaire was used in seven districts followed by necessary modifications for final data collection [13]. Division based rice-wheat-maize areas damaged, economic losses and contributions of different climate extremes were sorted out and graphs were prepared using Excel software. Spatial distribution maps on area damages and economic losses for rice, wheat-maize and three crops together were prepared using IDRISI.3.2. Socio-ecological vulnerabilities and area coverages were determined based on total score for a district followed by preparation of maps using IDRISI3.2. Scoring criteria are shown in Tables 1 and 2. The highest score was assigned when damage was the least and lowest score indicates the highest vulnerable areas. Arithmetic, geometric and weighted means and respondents to disaster preparedness and disaster knowledge management were determined as shown below:

$\mathrm{WM}=\left(\left(\mathrm{CYL}_{\text {score }}\right) \times\left(\mathrm{FL}_{\text {score }}\right) \times\left(\mathrm{SAL}_{\text {score }}\right) \times\right.$ $\left.\left(\mathrm{HHI}_{\text {score }}\right) \times\left(\mathrm{DPR}_{\text {score }}\right)\right)^{\wedge} 1 / 5 \times 0.5+\left(\left(\mathrm{HS}_{\text {score }}\right) \times\right.$ $\left.\left(\mathrm{DRT}_{\text {score }}\right)\right)^{\wedge} 1 / 2 \times 0.3+\left(\left(\mathrm{DKM}_{\text {score }}\right) \times\left(\mathrm{WL}_{\text {score }}\right)\right)^{\wedge} 1 / 2 \times$ 0.2

$\mathrm{WM}=$ weighted mean, $\mathrm{DRT}=$ drought, $\mathrm{WL}=$ waterlogging, $\mathrm{CYL}=$ cyclone, $\mathrm{DPR}=$ disaster preparedness, $\mathrm{DKM}=$ disaster knowledge management, $\mathrm{HHI}=$ household income, $\mathrm{SAL}=$ salinity, HS = hailstorm and FL = flood. 
Table 1 Scoring systems for drought, flooding and waterlogging damages during 2009-2014.

\begin{tabular}{llllllllll}
\hline \multicolumn{2}{c}{ Drought } & \multicolumn{2}{c}{ Flooding } & \multicolumn{2}{c}{ Waterlogging } & \multicolumn{2}{c}{$\begin{array}{c}\text { Disaster knowledge } \\
\text { management }\end{array}$} & Salinity \\
\hline $\begin{array}{l}\text { Affected HH } \\
\text { (“000”) }\end{array}$ & Score & $\begin{array}{l}\text { Affected } \\
\text { HH (“000”) }\end{array}$ & Score & $\begin{array}{l}\text { Affected HH } \\
\text { (“000”) }\end{array}$ & Score & \% Respondent & Score & Affected HH & Score \\
\hline$<0.1$ & 100 & $<1$ & 100 & $<0.1$ & 100 & $<40$ & 10 & $<50$ & 90 \\
$0.1-0.5$ & 90 & $1-5$ & 80 & $0.1-0.5$ & 90 & $40-50$ & 30 & $50-500$ & 70 \\
$0.5-1$ & 80 & $5-10$ & 60 & $0.5-1$ & 80 & $50-60$ & 50 & $500-5,000$ & 50 \\
$1-5$ & 70 & $10-15$ & 40 & $1-5$ & 70 & $60-70$ & 70 & $5,000-10,000$ & 20 \\
$5-10$ & 60 & $15-25$ & 30 & $5-20$ & 50 & $>70$ & 90 & $10,000-50,000$ & 10 \\
$10-20$ & 40 & $25-35$ & 20 & $20-50$ & 30 & & & $>50,000$ & 5 \\
$>20$ & 20 & $35-50$ & 10 & $50-75$ & 10 & & & & \\
\end{tabular}

Table 2 Scoring systems for cyclone and hailstorm damages during 2009-2014.

\begin{tabular}{llllllll}
\hline \multicolumn{2}{c}{ Cyclone } & \multicolumn{2}{c}{ Hailstorm } & \multicolumn{2}{c}{ HH income (\$) } & \multicolumn{2}{c}{ Disaster preparedness } \\
\hline $\begin{array}{lllll}\text { Affected } \\
\text { HH (“000”) }\end{array}$ & Score & Affected HH (“000”) & Score & Range & Score & (\% Respondent) & Score \\
\hline$<10$ & 100 & $<0.1$ & 100 & $<100$ & 10 & $<10$ & 10 \\
$10-20$ & 80 & $0.1-0.5$ & 90 & $100-200$ & 20 & $10.0-20$ & 20 \\
$20-40$ & 60 & $0.5-1$ & 80 & $200-400$ & 30 & $20-30$ & 30 \\
$40-80$ & 40 & $1-5$ & 70 & $400-800$ & 40 & $30-40$ & 40 \\
$80-100$ & 20 & $5-10$ & 50 & $800-1,200$ & 50 & $40-50$ & 50 \\
$100-120$ & 10 & $10-20$ & 40 & $1,200-1,600$ & 60 & $50-60$ & 60 \\
$>120$ & 5 & $20-30$ & 20 & $1,600-2,000$ & 70 & $60-70$ & 70 \\
& $>30$ & 10 & $2,000-3,000$ & 80 & $70-80$ & 80 \\
\end{tabular}

Geometric mean $(\mathrm{GM})=\left(\operatorname{Attr}_{1} \times \operatorname{Attr}_{2} \times \ldots \times\right.$ $\left.\operatorname{Attr}_{9}\right)^{\wedge}(1 / 9)$

Arithmetic mean $(\mathrm{AM})=($ Sum of all attributes $) / 9$

$\%$ Respondent $/ \mathrm{HH}=$ (Sample size engaged Control)/Total sample size $\times 100$

Potential exposure of rice, wheat and maize crops to climate extremes and/or natural hazards was delineated based on growing seasons of selected crops $[14,15]$ with probable occurrence times of episodic events [16-18].

Since drought is severe in winter season in Bangladesh, Landsat images were analyzed to estimate water availability in dry season during 1975-2015. A total of 16 scenes of Landsat MSS, TM and OLI imagery from path 135-139 and row 42-46 to cover entire Bangladesh were downloaded from USGS archives and analyzed digitally. These scenes were mosaic to get the entire Bangladesh. Space-borne satellite imageries (Landsat, MSS/TM/OLI) available between February and April of the year 1975, 1989, 2005 and 2015 were used to identify available water and to quantify its changes. Both the supersized and unsupervised classification techniques were applied for water and land mapping. Unsupervised classification used information from the image itself to identify spectral clusters, which are interpreted as classes. Supervised classification was used on the basis of Region of Interest (ROIs), where the training areas (collect from Google map) are regions of terrain with known properties or characteristics. Besides an index was used to identify the water bodies namely Normalized Different Water Index (NDWI). Remote sensing image analysis was done using ENVI (version 4.3) and ArcGIS software (version 9.3) was applied to digitize and analyze all the classified maps.

\section{Results}

Studied crop area damages were the highest 
because of flooding followed by drought, hailstorm and waterlogging, respectively (Fig. 1). Almost similar trends were followed for economic losses. The contributions of flood to area damages and economic losses were $34.38 \%$ and $37.23 \%$, respectively (Fig. 2). Area damages because of other hazards varied from $1.0 \%$ to $15.5 \%$ and that of economic losses varied from $1.2 \%$ to $15.1 \%$. The least rice area $(<500$ ha to 4,000 ha) damages were found in south-west and south-east (hilly regions) regions of the country (Fig. 3a). The highest rice area (60,000-95,000 ha) damages were in Sylhet region. Rice area damages in the central part of the country were about $10 \%-14 \%$. The economic loss in rice production was the highest $\left(85,000-95,000 \quad \mathrm{Tk}^{-1} \mathrm{ha}^{-1}\right) \quad\left(\$ 1,000-1,118 \quad \mathrm{ha}^{-1}\right) \quad$ in Satkhira district and the least $\left(<35,000 \mathrm{Tk} \cdot \mathrm{ha}^{-1}\right.$ or $\$ 411 \mathrm{ha}^{-1}$ ) in Dinajpur, Jashore, Lakhipur and Rangamati districts that cover about $9 \%$ areas of the country (Fig. 3b). In about $62 \%$ areas of the country, losses in rice production were 45,000-65,000 $\mathrm{Tk} \cdot \mathrm{ha}^{-1}$
(\$529-764 ha $\left.{ }^{-1}\right)$.

Wheat and maize crops mostly grown in north-west region of the country and damaged areas were about 12\% (Fig. 4a). The least area damages were found mainly in southern and south-east regions of the country. Economic losses because of wheat/maize area damage ranged from $<10,000 \mathrm{Tk}^{-1} \mathrm{ha}^{-1}$ to $>$ 85,000 Tk$\cdot \mathrm{ha}^{-1}$ (\$119-1,000) depending on severity of natural hazards (Fig. 4b). The highest damaged areas were about $29 \%$ having economic loss of $\$ 535-773$ $\mathrm{ha}^{-1}$ and the least damaged areas were found in southern Bangladesh covering about 1.5\% areas of the country and caused economic loss of $<\$ 119 \mathrm{ha}^{-1}$. Considering all three crops, damages were $<5,000$ ha in about 25\% areas and 20,000-30,000, 5,000-10,000, $30,000-40,000$ and $10,000-20,000$ ha in $18.64,17.43$, 15.68 and 14.07 percent areas of the country, respectively (Fig. 5a). The economic losses ranged from $<35,000$ to $>175,000 \mathrm{Tk}^{-1} \mathrm{C}^{-1}(<\$ 415$ to $>\$ 2,080)$ (Fig. 5b).

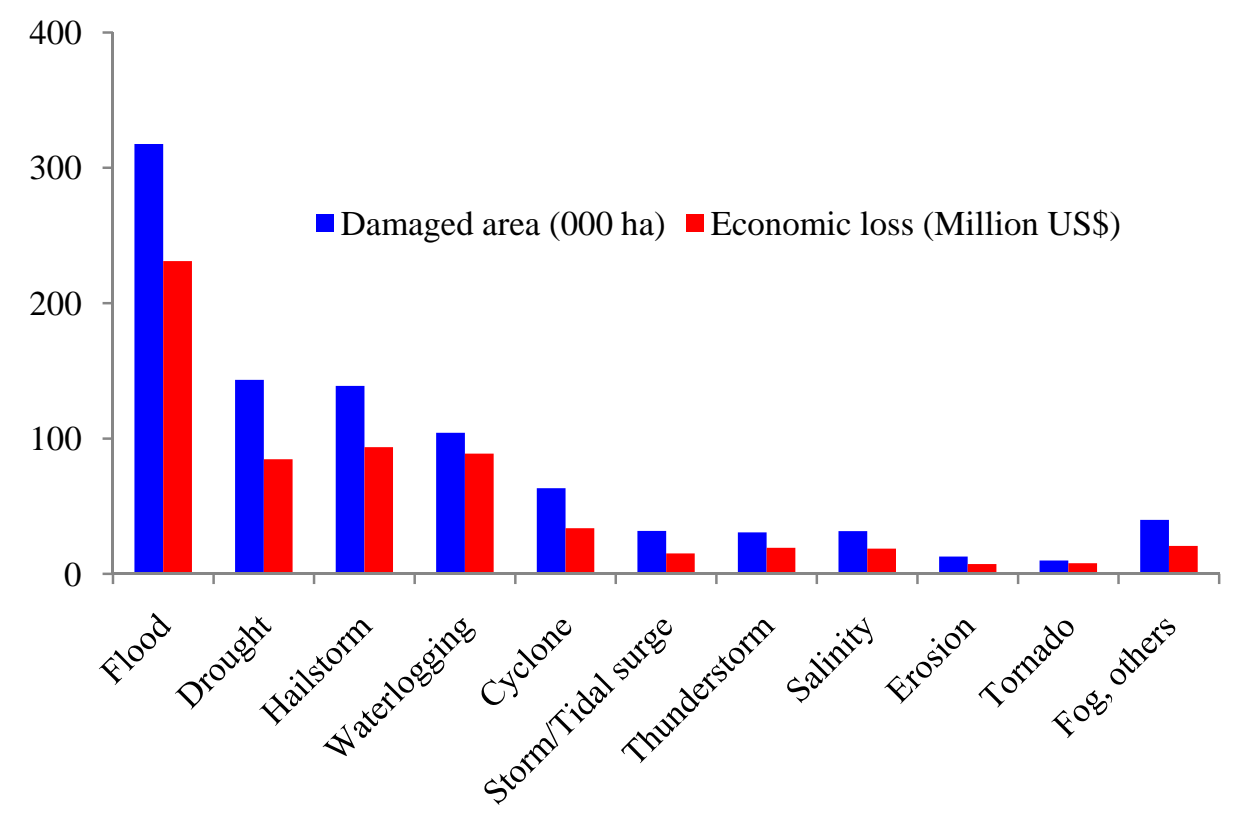

Fig. 1 Rice-wheat-maize area damages and economic losses caused by different natural hazards in Bangladesh during 2009-2014. 


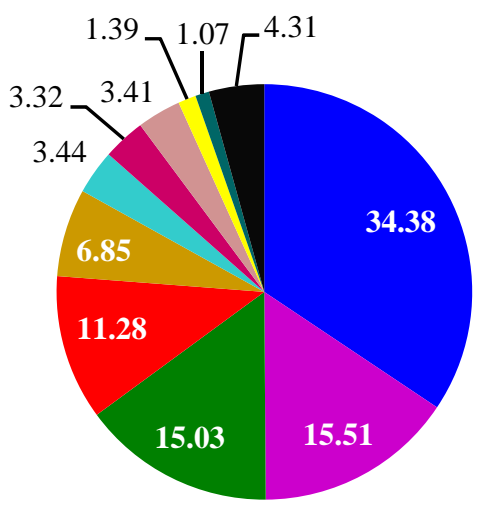

(a)

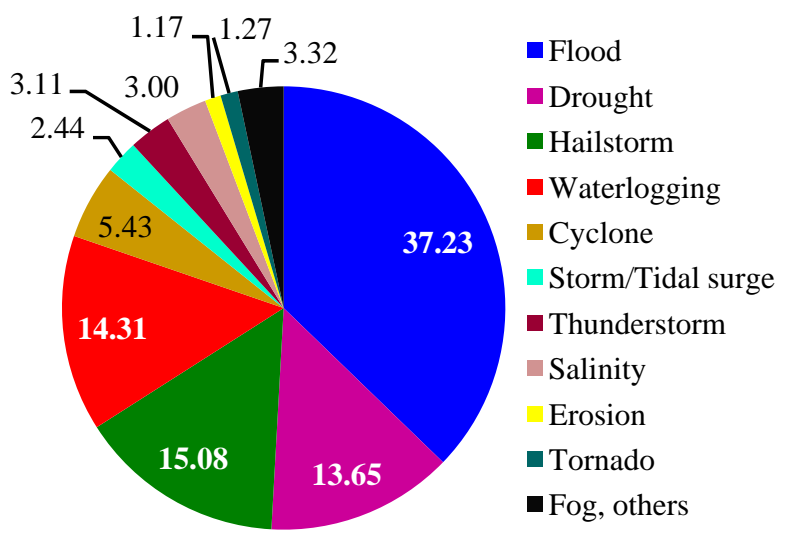

(b)

Fig. 2 Contribution (\%) of different natural hazards on (a) area damages and (b) economic losses in rice-wheat-maize crop production in Bangladesh during 2009-2014.
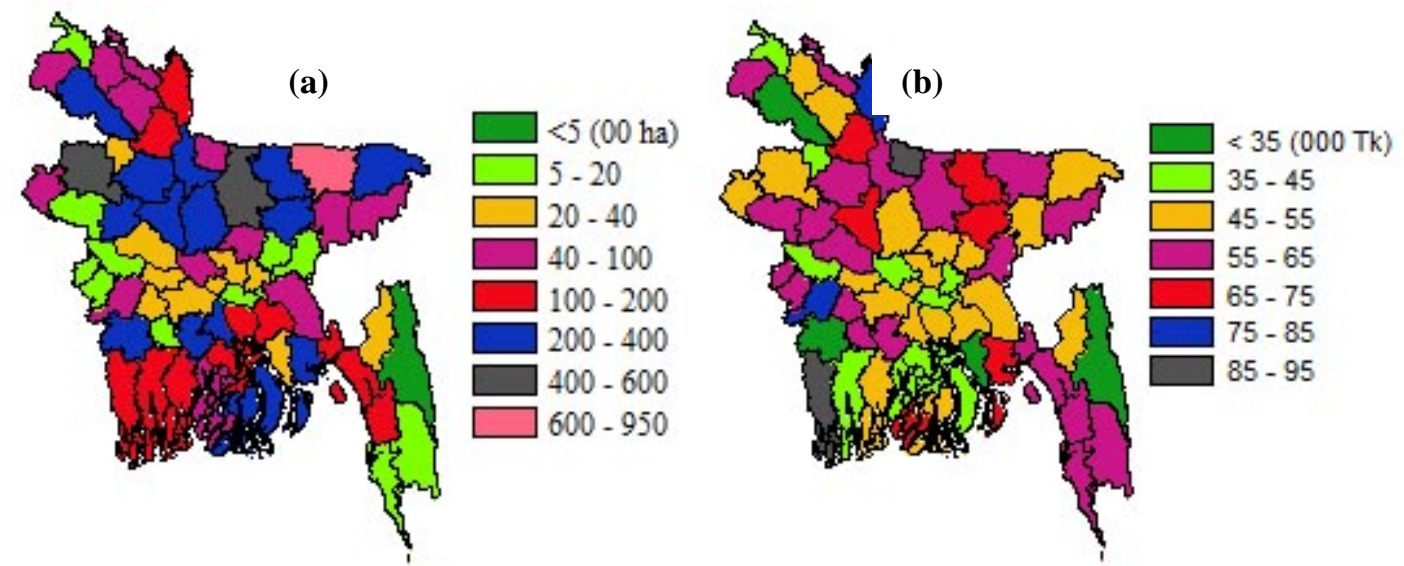

Fig. 3 Spatial distribution of (a) rice areas damages and (b) its economic losses in Bangladesh because of natural hazards during 2009-2014.
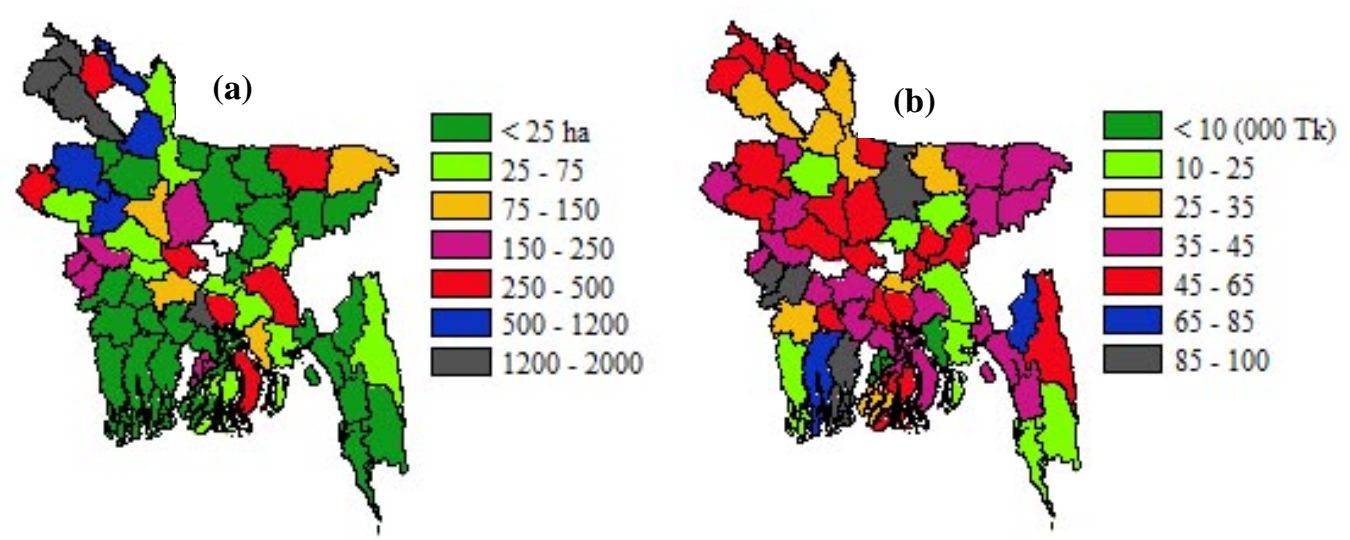

Fig. 4 Spatial distribution of climate extremes affected (a) wheat-maize areas and (b) economic losses in Bangladesh during 2009-2014. White patch indicates non-availability of data. 

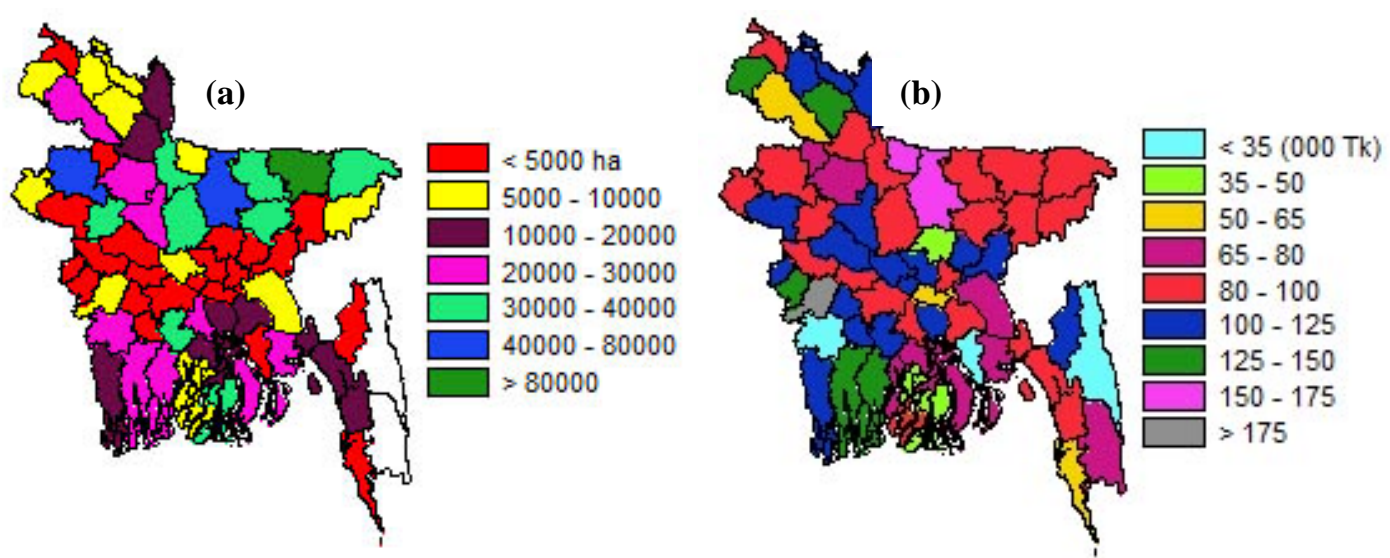

Fig. 5 Spatial distribution of rice-wheat-maize (a) area damages by natural hazards and (b) economic losses in Bangladesh during 2009-2014, Bangladesh.

The most socio-ecological vulnerable areas are situated in the north-east part of the country that covers $4 \%-9 \%$ areas depending on average, weighted and geometric mean scoring (Fig. 6). Based on geometric and weighted mean scoring, 36\%-47\% areas of the country are vulnerable because of natural hazards that frequently occur in Bangladesh (Figs. 6a and $6 b)$. Moderately vulnerable areas covered $18 \%$ to $33 \%$ areas of the country. Based on average scoring, about $45 \%$ areas are slightly or not vulnerable but based on geometric and weighted means these areas are $25.51 \%$ and $38.17 \%$, respectively. Moreover, rice yield losses showed comparatively better relations with geometric and weighted mean score than average score (Fig. 7).

\section{Discussions}

Crop area damages by different natural calamities are very common in Bangladesh. Out of 62,823 ha of land, about $80 \%$ croplands were damaged by natural hazards during 2009-2014 [13]. Among those hazards, floods, cyclones, hailstorms and droughts are occurring very frequently (Fig. 8). For example, flooding in 1988 and 1998 affected vast areas of the country (Fig. 9). Moreover, climate change associated sea level rise is likely to increase flooding intensity in southern coast of Bangladesh in future [19]. After 2003 its frequencies are increasing although not much devastating compared to flood in 1998. Since rice crops are cultivated year-round, it is more frequently affected by natural hazards than other crops. Flood alone caused about $\$ 230$ million loss during 2009-2014 and all together it was about \$612 million loss (Fig. 10). The damage patterns and economic losses vary depending on exposure of the crop to variable intensities of natural calamities in a particular location such as hailstorms and thunderstorms were more damaging for wheat and maize crops in Rajshahi and Rangpur regions (northern part) of the country (Fig. 11). In 2007, cyclone Sidr was responsible for loss of \$3 billion in crop sector of Bangladesh [8]. Cyclone Aila affected about four million people and destroyed 141,720 ha of cropland [20]. FAO [5] also reported that crop sector absorbs $42 \%$ of damage and losses because of natural hazards. Rice (Aus, Aman and Boro), wheat and maize crops are grown in different seasons in a year and thus they expose to different kinds of climate extremes (Fig. 12). Among the studied crops, rice faces most of them and so area and economic damages are more with rice crop.

Floods in different forms affect northern, north-east and central regions of the country almost every year [7]. During 1960-1986, there was only one mega flood; but five mega floods occurred during 1987-2013 [21]. Sudden excessive rainfall, tidal/storm surge and upstream flow aggravate flooding damages [22]. Flooding damages in Dhaka division, the central part of the country, are more because of sudden increase in 

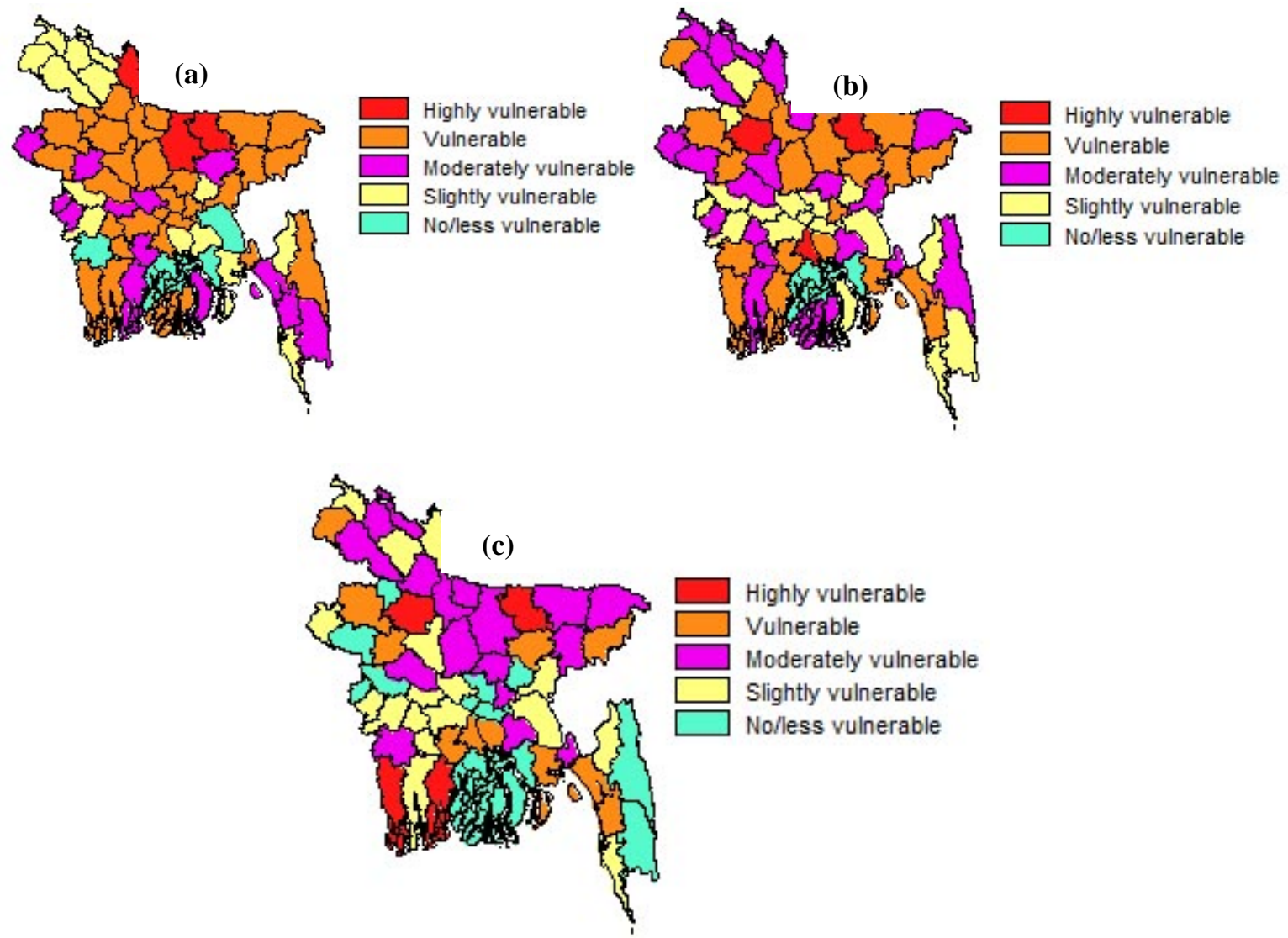

Fig. 6 Socio-ecological vulnerable zones in Bangladesh based on (a) weighted, (b) geometric and (c) arithmetic means.
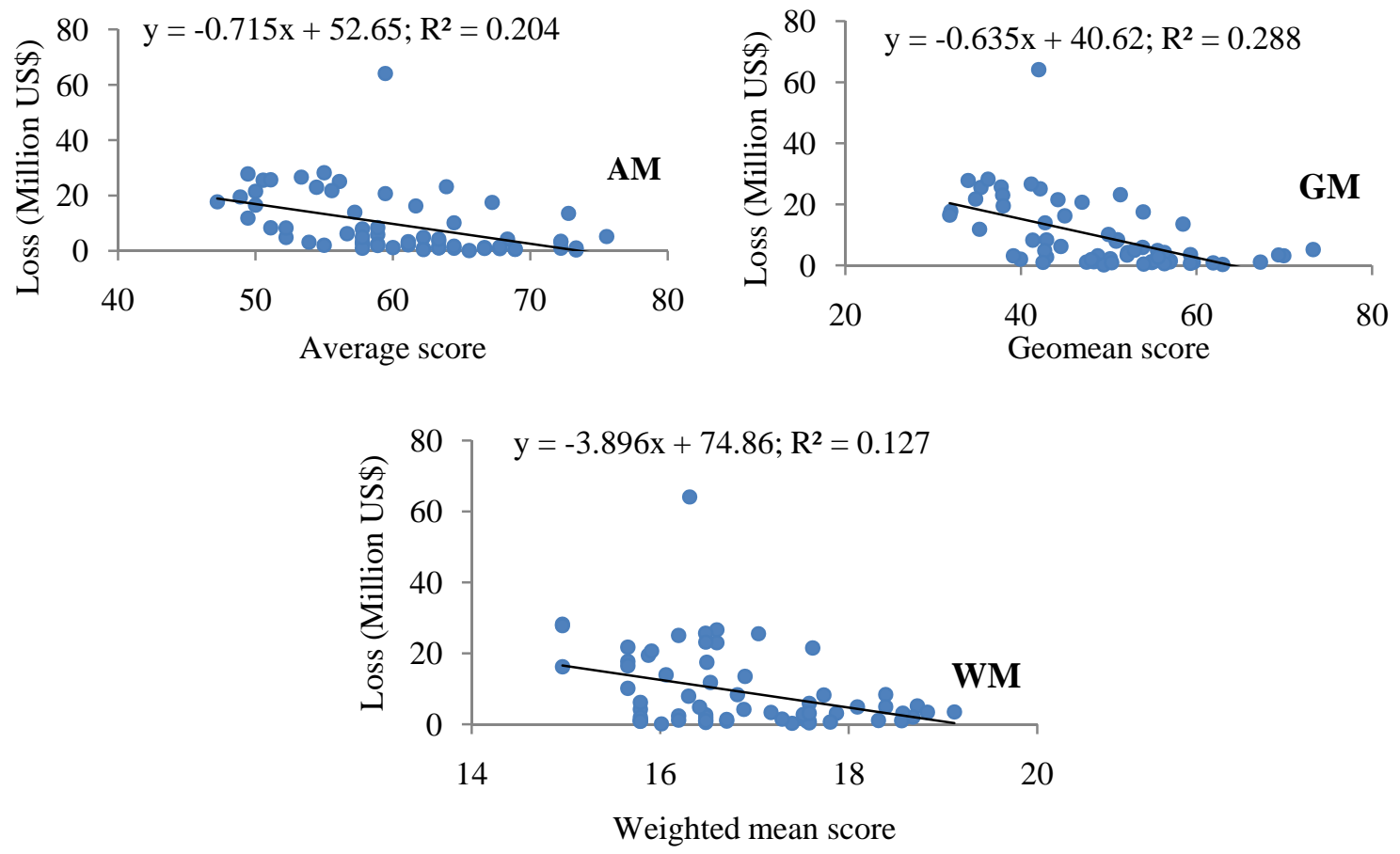

Fig. 7 Relationships of socio-ecological vulnerability score with economic loss of paddy crop damages in Bangladesh during 2009-2014. 


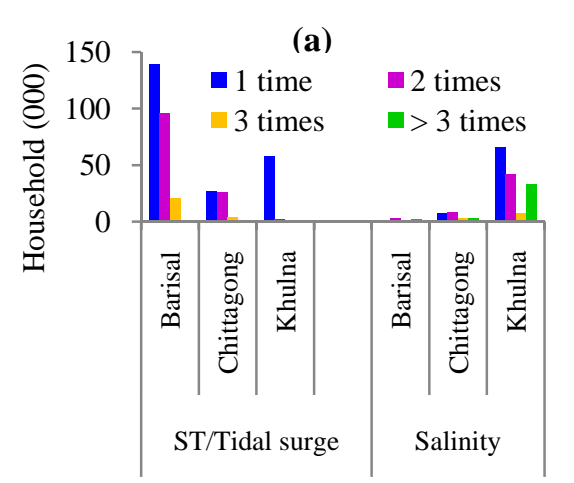

(b)
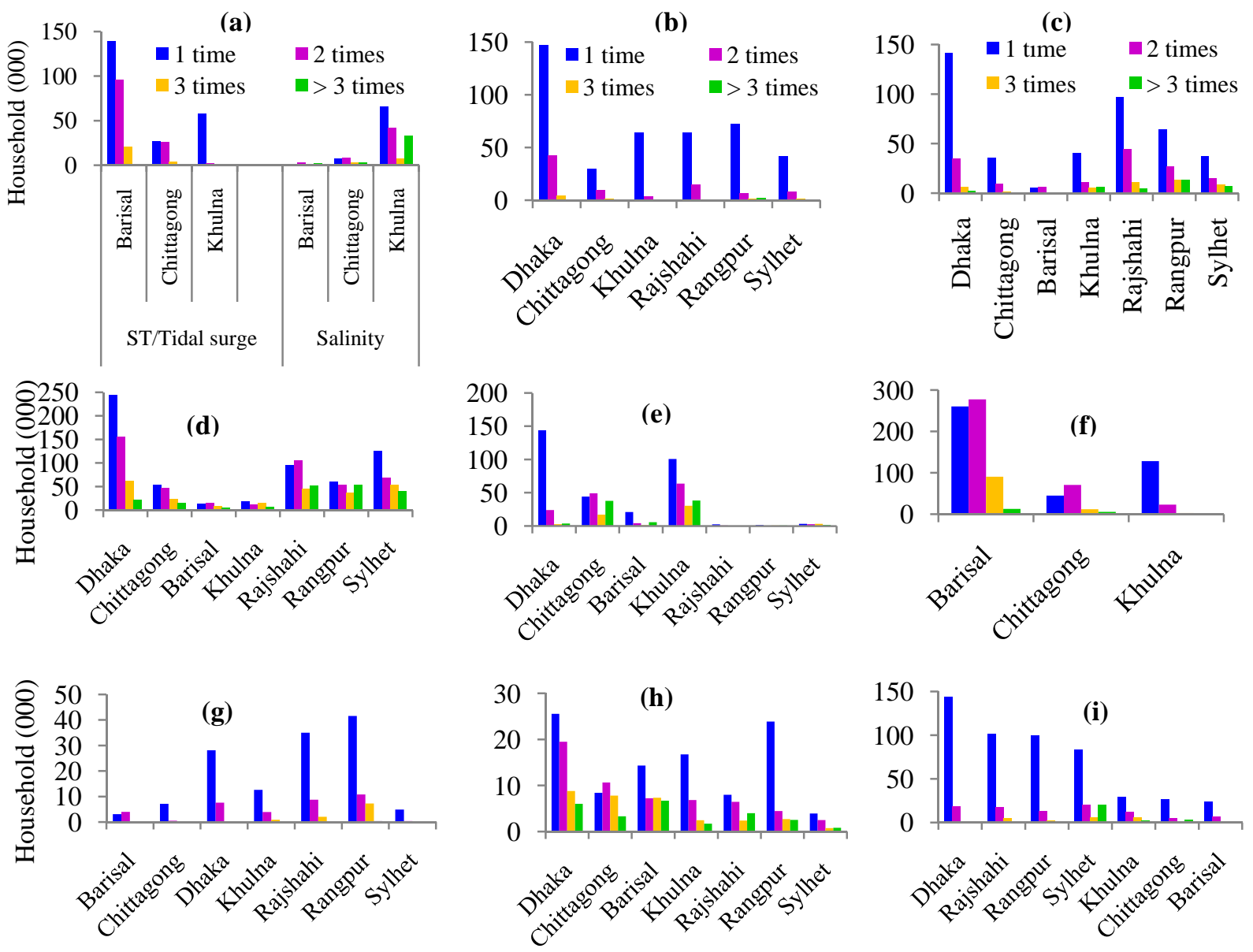

Fig. 8 Frequencies of (a) storm/tidal surge and salinity, (b) hailstorm, (c) drought, (d) flood, (e) waterlogging, (f) cyclone, (g) tornado, (h) erosion and (i) thunderstorm that affected households during 2009-2014 in Bangladesh.

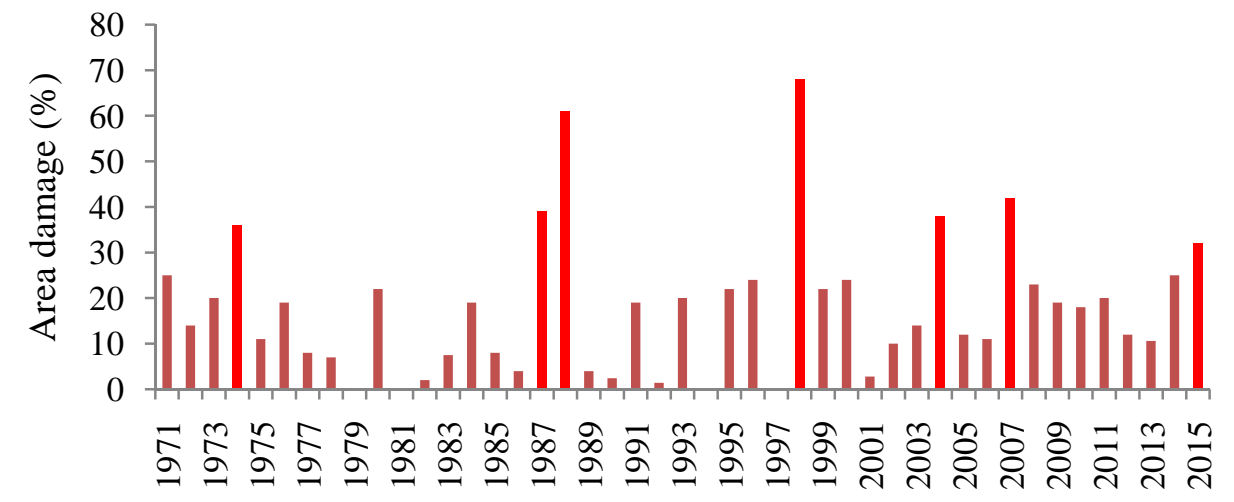

Fig. 9 Historical flood affected areas in Bangladesh. 


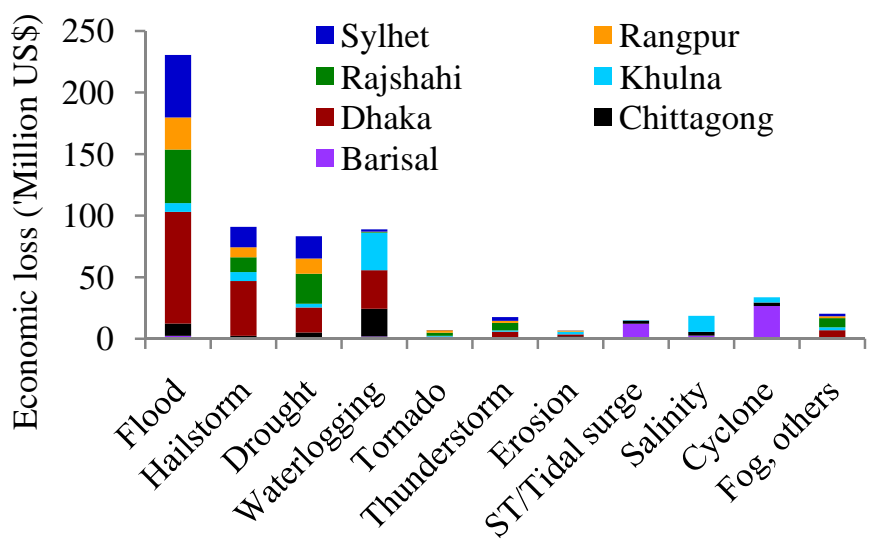

Fig. 10 Economic losses because of rice crop area damage by natural hazards in Bangladesh during 2009-2014.

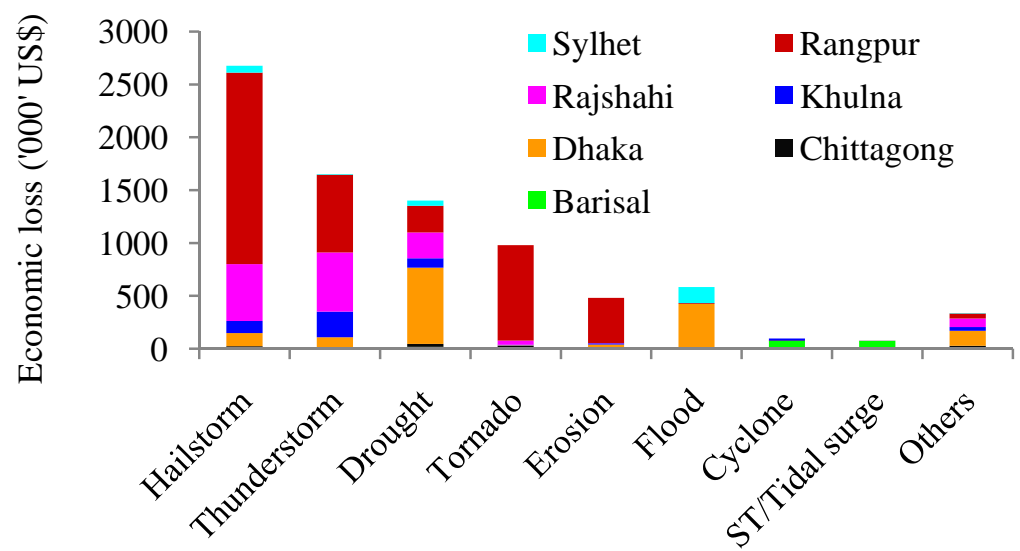

Fig. 11 Contribution of different climate extremes on economic losses with wheat-maize cultivation in Bangladesh during 2009-2014.

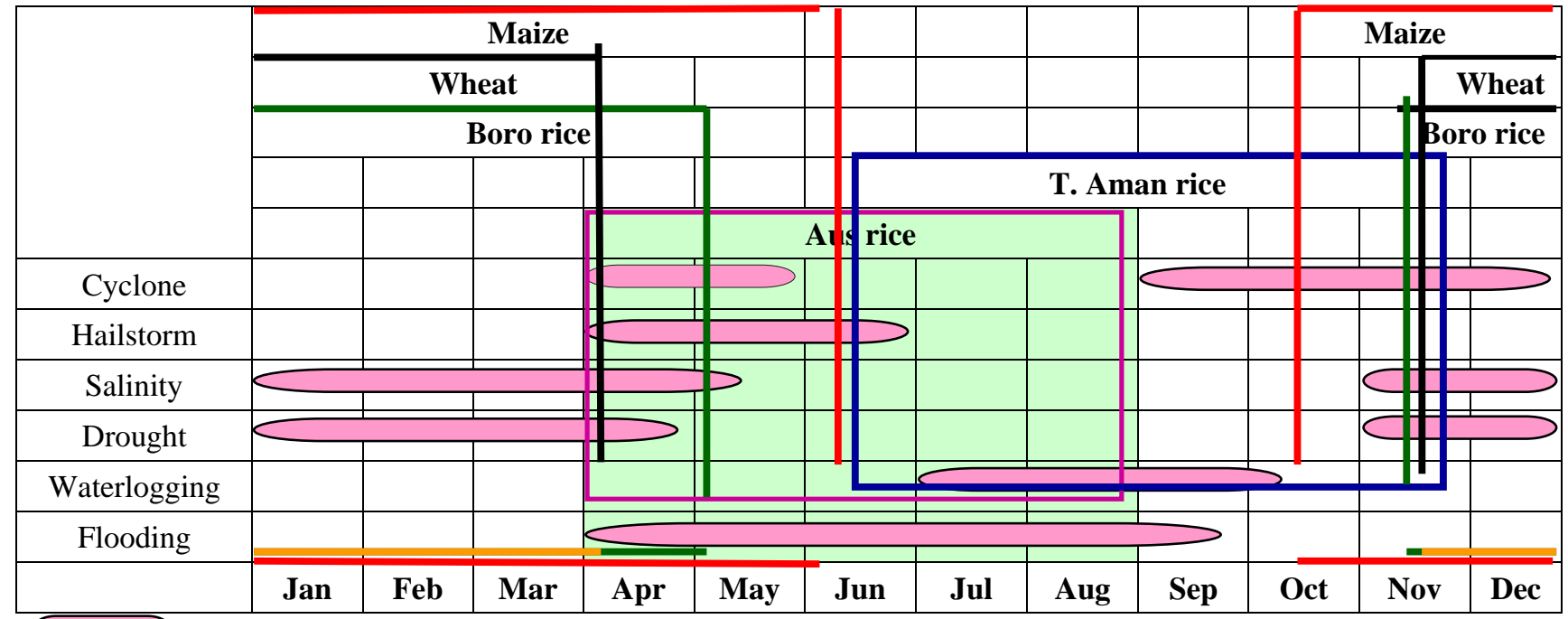

Shows probable occurrences times of natural hazards.

Rectangles in different colors show sowing to harvesting times for selected crops.

Fig. 12 Potential exposure scenarios of rice, wheat and maize crops to climate extremes in Bangladesh; maize crop is sown on 15 Feb.-March and October-November in a year. 


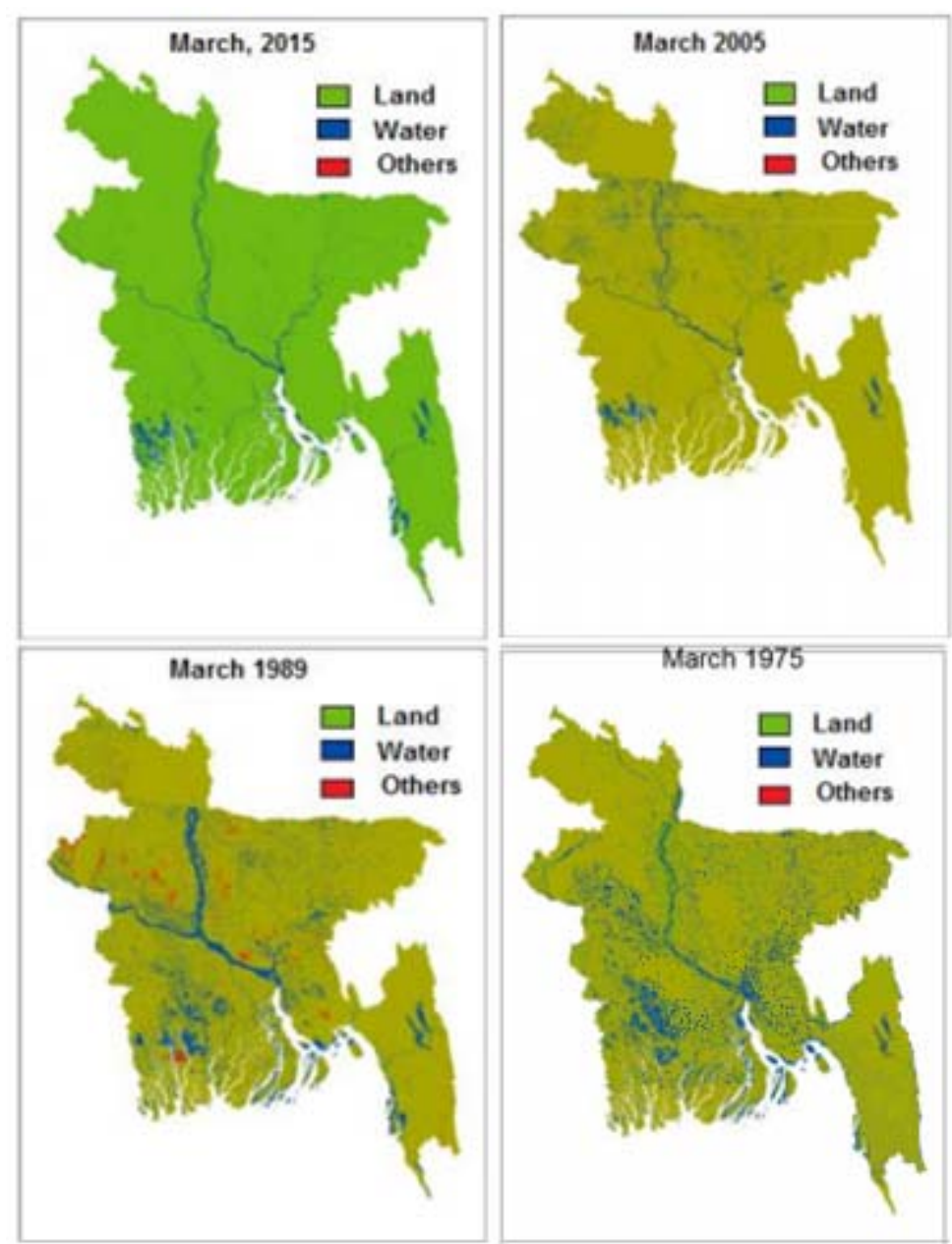

Fig. 13 Trends in surface water availability in Bangladesh during last four decades (1975-2015).

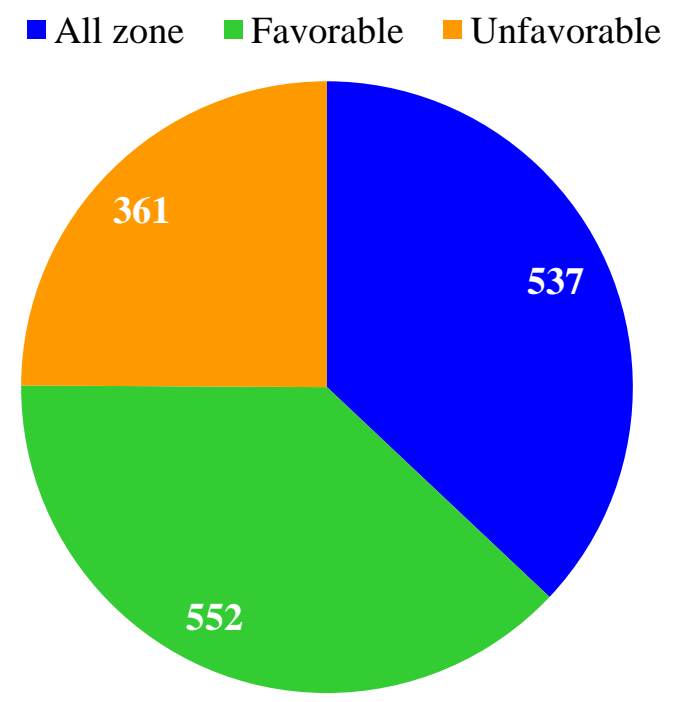

Fig. 14 Loss pattern $\left(\$ \cdot \mathrm{ha}^{-1}\right)$ in wheat-maize production because of natural hazards in Bangladesh. 
upstream flow but reduced water current towards the sea that results in stagnant water conditions for a longer period than usual floods.

All studied crops suffered from drought in Bangladesh (Figs. 9 and 10). Sometimes supplemental irrigation waters are applied to improve crop yield; but in many instances no irrigation is provided because of unavailability of surface water. Our analysis on Landsat images for four decades (1975-2015) shows that surface water availability is decreasing (Fig. 12). Surface water availabilities were 5.76, 4.34, 3.92 percent in March of 1975, 1989 and 2005, respectively, which has reduced to 3.62\% during 2015. This gradual change in surface water availability indicates that scope for mitigating drought effects through surface water is decreasing in Bangladesh. On the other hand, land surface area was 93.81, 93.47, 96.53 and 96.01 percent in March of 1975, 1989, 2005 and 2015, respectively. The increased land surface area, if under cultivation, might have helped in increased total productivity in Bangladesh. Moreover, the economic losses in wheat-maize cultivation due to natural hazards can be compensated by extensive cultivation of these crops in comparatively unfavorable production zone (Fig. 13). North and north-west regions are the wheat-maize growing areas where economic loss was the highest (\$552 ha ${ }^{-1}$ ) compared to unfavorable ecosystem (Fig. 14). This indicates that expanding cultivated areas in newer regions could be one of the adaptation strategies to combat natural hazards in Bangladesh considering land and crop suitability.

The higher economic loss in wheat-maize cultivation was related with crop damages by hailstorm and thunderstorm (Fig. 10); but flood was the most damaging for rice crops (Fig. 9). In general, three to four dominant climate extremes were responsible for major share of economic losses. For example, drought, flood, hailstorm and waterlogging were responsible for about $80 \%$ of economic losses in rice production. About 81\% economic losses occurred in wheat/maize crops due to drought, hailstorm, tornado and thunderstorm. If three studied crops are considered together, about $80 \%$ economic losses were caused by drought, flood and hailstorms. Since intensities of natural hazards are location specific, breeding suitable varieties that can withstand climate extremes are highly desirable for future agriculture in Asia including Bangladesh. Besides, planting/sowing schedules need to be adjusted in such a way that critical crop growing stages do not coincide with general prevalence of natural calamities. For example, flash flooding during Boro season (dry season irrigated rice) damages rice crop in late April to May, especially in low lying areas. So, selection of short duration rice variety and its planting should be done in such a way that the crop can be harvested by mid April.

The affected households are distributed in different parts of the country because of varied nature of climate extremes occurring in Bangladesh. About 13\% $\mathrm{HH}$ and $12.64 \%$ population live in disaster prone areas of the country and their sensitivity to exposed hazards depends on financial capabilities and intensity of natural calamities [13]. For example, stakeholders having low income in Dhaka, Rangpur and Khulna divisions are more vulnerable to climate changed related shock than other parts of the country [23]. In general, proportion of damage and economic loss decreases as total $\mathrm{HH}$ income increases [13]. The economic shock could be short- and long-term depending on damages on natural resources like sand deposition on fertile land or destruction of water reservoirs that were used for irrigation purposes. In Bangladesh, however, sensitivity to tropical storms and flood vulnerabilities are decreasing because of increased resilience resulting from higher $\mathrm{HH}$ income and government actions for disaster reduction [24]. They also reported that natural disaster can impair short- and long-term development of a country.

Generally farmers and government take initiatives after every natural disaster to increase crop production 
in Bangladesh that ameliorates sufferings of people because of disaster exposure [25]. Common adaptations to natural hazard exposures are crop switching, migration and increased labor supply [26]. The other adaptation options could be improvement of post disaster recovery efficiency through financial support, supplying seeds and other inputs based on seasonal suitability. For example, late recession of flooding can be overcome through the supply of tall and sturdy rice seedlings of BRRI dhan76 and BRRI dhan77 or supplying rice seedlings of BR22, BR23 and BRRI dhan46 for late planting along with production packages. Since recurrent disasters are very common in Bangladesh, appropriate initiatives by the government and international communities for increased food availability, employment generations can alleviate post disaster sufferings. Floating agriculture, water and salinity tolerant varieties, capacity building and awareness build up are the adaptation strategies for flood management.

\section{Conclusion}

Bangladesh is a country where natural hazards land every year and the frequencies of extreme climate events are increasing. We have investigated the effects of natural hazards on rice, wheat and maize crops based on existing and Landsat image data. About 2-4.7 million HHs were affected by different natural hazards in different regions of the country. Flood affected HHs were predominant in northern and north-east regions of the country and their sensitivity to exposed hazards depends on financial capabilities. Flooding was the most damaging climate extreme followed by drought and hailstorm. The most vulnerable areas are situated in the south-west and north-west part of the country. Rice crops are frequently exposed to climate extremes and caused economic loss of \$228 million during 2009-2014. Economic losses were $<\$ 110$ to $1,000 \mathrm{ha}^{-1}$ because of wheat/maize areas damaged by natural hazards. Common adaptations to natural hazard exposures are crop switching and migration. The other adaptation options could be improvement of post disaster recovery efficiency through financial support, supplying seeds and other inputs based on seasonal suitability. Coordinated efforts among different stakeholders are needed for mitigation and adaptation against climate change induced extreme events in Bangladesh.

\section{Acknowledgement}

We greatly acknowledge financial support from Krishi Gobeshona Foundation, BARC Complex, Dhaka, Bangladesh for conducting this research.

\section{Conflict of Interest}

There are no conflicts of interest among authors or institutes concerned.

\section{References}

[1] BBS (Bangladesh Bureau of Statistics). 2017. Year Book of Agricultural Statistics-2016. Statistics and Informatics Division, Ministry of Planning, Government of the People's Republic of Bangladesh.

[2] Bala, B. K., and Hossain, M. A. 2010. "Modeling of Food Security and Ecological Footprint.” Environ. Dev. Sustain. 12: 511-29.

[3] WB (World Bank). 2010. The Economics of Adaptation to Climate Change. Synthesis Report, World Bank.

[4] Bhuiyan, N. I., Jabbar, M. A., and Paul, D. N. R. 2007. “Feeding Extra Million.” Paper presented in the HYV Workshop on October, 2007. Bangladesh Rice Res Inst., Gazipur, pp. 35-43.

[5] FAO (Food and Agriculture Organization). 2015. "The Impact of Disasters on Agriculture and Food Security.” Food and Agriculture Organization of the United Nations. www.fao.org/resilience.

[6] DoE (Department of Environment). 2007. "Climate Change and Bangladesh.” Ministry of Environment and Forest. Government of the People's Republic of Bangladesh, Dhaka.

[7] Ahmed, M., and Suphachalasai, S. 2014. "Assessing the Cost of Climate Change and Adaptation in South Asia.” Asian Development Bank, Mandaluyong City, Philippines.

[8] Hasegawa, K. 2008. Features of Super Cyclone Sidr to Hit Bangladesh in Nov. 07 and Measures for Disaster from Results of JSCE Investigation, Sapporo, Japan: 
Foundation of River and Watershed Environment Management, Hokkaido Office. http://www.wfeo.org/ documents/download/DRM_Water-Related\%20Disasters. pdf.

[9] Maniruzzaman, M., Muttaleb, M. A., Choudhury, A. K., Akhter, S., Ahmed, F., Aziz, M. A., Rahman, M. M., Miah, M. M. U., Biswas, J. C., Hamid, M. A., and Kalra, N. 2017. "Characterization of Inter-seasonal Characterization of Inter-seasonal Climatic Variability through Dry Season Rice Productivity in the North-West Region of Bangladesh.” Italian J. Agrometeorol. 1: 5-18. http://doi:10.19199/2017.1.2038-5625.005.

[10] Ishtiaque, S., Sen, R., Jahan, M. A. H. S., Choudhury, A. K., Akhter, S., Ahmed, F., Biswas, J. C., Maniruzzaman, M., Miah, M. M. U., Rahman, M. M., Khan, A. S. M. M. R., Kalra, N., and Hossain, M. B. 2018. "Simulating Wheat Yield under Changing Temperature, Carbon Dioxide and Solar Radiation Levels in Bangladesh.” Global J. Sci. Frontier Res. 18: 27-36.

[11] IPCC (Intergovernmental Panel on Climate Change). 2018. IPCC SR1.5. Global Warming of $1.5^{\circ} \mathrm{C}$. Summary for Policymakers. WMO, UNEP.

[12] GED (General Economics Division). 2017. Hotspots Wise Problems and Challenges. Bangladesh Delta Plan 2100. Bangladesh Planning Commission. Government of the People's Republic of Bangladesh, pp. 154-8.

[13] BBS (Bangladesh Bureau of Statistics). 2015. Bangladesh Disaster-Related Statistics 2015: Climate Change and Natural Disaster Perspectives. Statistics and Informatics Division, Ministry of Planning, Government of the People's Republic of Bangladesh.

[14] BRRI (Bangladesh Rice Research Institute). 2018. Modern Rice Cultivation, 21st ed., Pub. \# 5, p. 91.

[15] BARI (Bangladesh Agricultural Research Institute). 2000. Handbook on Agro-Technology, 2nd ed. BARI, Gazipur, pp. 2-31.

[16] BBS (Bangladesh Bureau of Statistics). 2016. Year Book of Agricultural Statistics-2015. Statistics and Informatics Division, Ministry of Planning, Government of the People's Republic of Bangladesh.

[17] Rahman, M. R., and Lateh, H. 2016. "Meteorological Drought in Bangladesh: Assessing, Analyzing and Hazard Mapping Using SPI, GIS and Monthly Rainfall
Data.” Environ. Earth Sci. 75: 1026. http://doi 10.1007/s12665-016-5829-5.

[18] Islam, M. M. 2013. Country Report: People's Republic of Bangladesh. ADRC Visiting Researcher Programme, FY2013B.

[19] MoA-FAO (Ministry of Agriculture-Food and Agriculture Organization). 2012. "Master Plan of Agricultural Development in the Southern Region of Bangladesh.” Ministry of Agriculture, Government of Bangladesh and United Nations Food and Agriculture Organization, Dhaka.

[20] Majumder, S. 2013. "The Economics of Early Response and Resilience: Bangladesh Country Study.” Accessed Sept. $14,2018$. http://assets.publishing.service.gov.uk/media/57a31e0000 e0/61114_Bangladesh_Background_Report.pdf.

[21] BDP-2100 (Bangladesh Delta Plan-2100). 2017. Bangladesh Delta Plan 2100. Government of the People's Republic of Bangladesh, Bangladesh Planning Commission, General Economics Division, September, 2017.

[22] CDMP (Comprehensive Disaster Management Programme). 2013. "Vulnerability to Climate Induced Drought: Scenario \& Impact." Ministry of Disaster Management and Relief. Department of Disaster Management Building, Mohakhali C/A, Dhaka.

[23] Azad, A. K., and Wadood, S. N. 2017. "Climate Change and Bangladesh Fisheries and Aquaculture: Evidences from the Household Income and Expenditure Survey (HIES) 2010 Data.” MPRA Paper No. 81552, Posted 25 September 2017. http://mpra.ub.uni-muenchen.de/81552/.

[24] Benson, C., and Clay, E. 2003. Economic and Financial Impacts of Natural Disasters: An Assessment of Their Effects and Options for Mitigation: Synthesis Report. Accessed Sept. 14, 2018. http://www.odi.org/sites/odi.org.uk/files/odi-seests/public ations-opinion-files/6149.pdf.

[25] Deininger, K., Savastano, S, and Carletto, C 2012. "Land Fragmentation, Cropland Abandonment and Land Market Operation in Albania.” World Dev. 40: 2108-22.

[26] Moniruzzaman, S. 2015. "Crop Choice as Climate Change Adaptation: Evidence from Bangladesh.” Ecol. Econ. 118: 90-8. 